Am J Obstet Gynecol. 2013 November ; 209(5): . doi:10.1016/j.ajog.2013.06.018.

\title{
Surgical site infection after hysterectomy
}

\author{
AeuMuro G. Lake, MD, Alexandra M. McPencow, MD, Madeline A. Dick-Biascoechea, MD, \\ Deanna K. Martin, MPH, and Elisabeth A. Erekson, MD MPH \\ Department of Obstetrics, Gynecology, and Reproductive Sciences at Yale University School of \\ Medicine, New Haven, Connecticut
}

\begin{abstract}
Objective-Our objective was to estimate the occurrence of surgical site infections (SSI) after hysterectomy and associated risk factors.
\end{abstract}

Study Design-We conducted a cross-sectional analysis of the 2005-09 American College of Surgeons National Surgical Quality Improvement Program participant use data files to analyze hysterectomies. Different routes of hysterectomy were compared. The primary outcome was to identify the occurrence of 30-day superficial SSI (cellulitis) after hysterectomy. Secondary outcomes were the occurrence of deep and organ-space SSI after hysterectomy. Logistic regression models were conducted to further explore the associations of risks factors with SSI after hysterectomy.

Results-A total of 13,822 women were included in our final analysis. The occurrence of postoperative cellulitis after hysterectomy was $1.6 \%(n=221)$. Risk factors associated with cellulitis were route of hysterectomy with an adjusted odds ratio (AOR) of 3.74 (95\% CI 2.26-6.22) for laparotomy compared with the vaginal approach, operative time $>75^{\text {th }}$ percentile $(\mathrm{AOR}=1.84,95 \%$ CI 1.40-2.44), American Society of Anesthesia Class $\geq 3$ (AOR 1.79, 95\% CI $1.31-2.43$ ), body mass index $\geq 40 \mathrm{~kg} / \mathrm{m}^{2}$ (AOR $2.65,95 \%$ CI $1.85-3.80$ ), and diabetes mellitus (AOR $1.54,95 \%$ CI 1.06-2.24) The occurrence of deep and organ-space SSI was $1.1 \%(n=154)$ after hysterectomy.

Conclusion-Our finding of the decreased occurrence of superficial SSI after vaginal approach for hysterectomy reaffirms the role for vaginal hysterectomy as the route of choice for hysterectomy.

\section{Keywords}

hysterectomy; postoperative complications; surgical site infection; surgical outcomes

\section{Introduction}

Recently, United States healthcare initiatives sponsored by the Centers for Medicare and Medicaid Services (CMS) and the Joint Commission on the Accreditation of Healthcare

Corresponding Author: AeuMuro Lake, MD, Yale University School of Medicine, Section of Urogynecology, 333 Cedar St, PO Box 208063, New Haven, CT 06519, (203) 737-4880, Fax (203) 785-2909, aeumuro.lake@ yale.edu.

Disclosure Statement: The authors report no conflict of interest.

Paper Presentation Information: This paper was presented at the 39th Annual Meeting of the Society of Gynecologic Surgeons on April 8-10 th, 2013 , in Charleston, South Carolina.

Condensation:We identified the following risk factors were associated with the occurrence of postoperative superficial SSI (cellulitis): hysterectomy route, operative time greater than the $75^{\text {th }}$ percentile (149 minutes), ASA class 3 or greater, diabetes mellitus, and obesity category (BMI $\geq 40 \mathrm{~kg} / \mathrm{m}^{2}$ ). Our finding of the decreased occurrence of superficial SSI after vaginal approach for hysterectomy reaffirms the role for vaginal hysterectomy as the route of choice for hysterectomy 
Organizations have targeted preventable hospital acquired infections, such as postoperative surgical site infections (SSI), as a priority in improving patient safety. Effective January 2012, CMS required all Medicare-Certified Hospitals to publically report clinical data and outcome measures in a "Systematic Clinical Database Registry for General Surgery," in the Hospital Inpatient Quality Reporting Program. ${ }^{1}$ The consequence for an institution or hospital not reporting will be a payment penalty as of October 2013. The two surgical procedures identified by CMS in this recent mandate for public reporting of postoperative SSI are colon surgery and hysterectomy.

Over the last two decades, remarkable advancements have been made in the choice of hysterectomy routes. Although the occurrence and risk factors of SSI after total abdominal hysterectomy (TAH) has been reported, ${ }^{2}$ neither the occurrence nor the risk factors of posthysterectomy SSI have been reported by hysterectomy route. ${ }^{2-4}$ Better understanding of risk factors for SSI after hysterectomy can help target efforts at reducing modifiable risks to prevent infections. Additionally, understanding risk factors for SSI after hysterectomy can lead to better risk-stratification in reporting quality outcomes. Our objective is to estimate the occurrence of 30-day postoperative SSI after all routes of hysterectomy and identify associated risk factors.

\section{Materials and Methods}

We conducted a secondary database analysis of the 2005-09 American College of Surgeons National Surgical Quality Improvement Program (ACS NSQIP) participant use data files to analyze women undergoing hysterectomies performed by gynecologic services. The ACS NSQIP is a national program for surgical quality improvement collecting uniform data on patients undergoing surgical procedures. Hospital participation in the ACS NSQIP program is voluntary and confidential. This information is collected by a formal chart review process in addition to 30-day postoperative follow-up on patients. ${ }^{5}$ Variables collected include: preoperative characteristics, surgical information, and 30 day postoperative complications. The ACS NSQIP database and its quality control measures are further described on their website: http://www.acsnsqip.org. Exemption status for this study was obtained in writing from the Yale Human Investigation Committee which serves as the Internal Review Board for Yale University.

Exclusion criteria included: 1) male gender, 2) women with the diagnosis of current pregnancy, 3) surgical procedure within 30 days prior to hysterectomy, 4) Current Procedural Terminology Coding System, 4th edition (CPT-4) code inconsistent with hysterectomy, 5) CPT-4 code indicating pelvic exenteration procedure at the time of hysterectomy, and 5) women with diagnosis of preoperative infection including sepsis, systemic inflammatory response syndrome (SIRS) and septic shock immediately prior to hysterectomy. After excluding for the above criteria the remaining participants were women who underwent hysterectomy.

Hysterectomy route was assigned based on CPT-4 coding of the primary procedure: TAH, abdominal supracervical hysterectomy ( $\mathrm{SCH}$ ), total vaginal hysterectomy (TVH), laparoscopic assisted vaginal hysterectomy (LAVH), total laparoscopic hysterectomy (TLH), and laparoscopic supracervical hysterectomy (LASCH). We further examined SSIs based on abdominal incisions: 1) laparotomy (TAH or SCH), 2) laparoscopic (LAVH, TLH, or LASCH), or 3) total vaginal hysterectomy. Finally, we examined SSIs based on vaginal cuff incisions: 1) no vaginal cuff incisions (SCH or LASCH) vs. 2) vaginal cuff incisions (TAH, TVH, LAVH, and TLH). 
Risk factors for SSI were explored and grouped into the following categories: demographic features, preoperative medical comorbidities, and intraoperative factors. Demographic features included age, race and ethnicity. Women were dichotomized into the two age categories (younger than 80 years and 80 years or older) due to a previously demonstrated nonlinear association between age and the log-odds of postoperative infection. ${ }^{6}$ Preoperative comorbidities included medical diagnoses, obesity, hysterectomy for gynecologic cancer, preoperative functional status, unintentional weight loss, preoperative laboratory data and American Society of Anesthesia (ASA) classification. Medical diagnoses considered included: diabetes mellitus, history of cerebrovascular accidents (CVA) with neurologic deficit, ascites, preoperative corticosteroid use, and obesity. Obesity was classified based on body mass index (BMI). Women were categorized as having normal weight (BMI $<30 \mathrm{~kg}$ / $\mathrm{m}^{2}$ ), obesity (BMI $\geq 30$ and $<40 \mathrm{~kg} / \mathrm{m}^{2}$ ) and morbid obesity (BMI $\left.\geq 40 \mathrm{~kg} / \mathrm{m}^{2}\right) .{ }^{7}$ Women undergoing hysterectomies for gynecologic cancer were identified based on CPT-4 codes consistent with lymph node dissection or radical debulking, the diagnoses of preoperative ascites, preoperative disseminated cancer, preoperative chemotherapy, and preoperative radiation therapy. Functional status was defined as a woman's ability to perform activities of daily living, including "bathing, feeding, dressing, toileting, and mobility" and was categorized as either "independent" or "dependent."

Unintentional weight loss was used as a marker of frailty and was defined as loss of more than $10 \%$ of body weight over the previous 6 months. Preoperative laboratory data was used to identify anemia and renal compromise. Anemia was defined as hematocrit (Hct) of $<36 \%$ based on the findings of Wu et al. ${ }^{8}$ and Heisler et al. ${ }^{9}$ Renal compromise was defined as a creatinine of $>1.5 \mathrm{mg} / \mathrm{dL}$ based on findings of Dowdy et al. ${ }^{10}$ Intraoperative factors explored included type of anesthesia, wound classification, intraoperative blood transfusion, and procedural difficulty. Concomitant procedures and procedural difficulty were accounted for by examining total work relative value units (RVUs) and total operative time. Procedures had between 1 and 8 CPT codes. In order to consider the complexity of all the different possible combinations of procedures, work RVUs for all concomitant procedures were totaled. Operative time was categorized as a dichotomous variable above and below the $75^{\text {th }}$ percentile based on previous work by Culver et al. demonstrating that operative time above the $75^{\text {th }}$ percentile is a risk factor for SSI. ${ }^{11}$ For hysterectomies in the ACS NSQIP dataset, the operative time above the $75^{\text {th }}$ percentile was 149 minutes.

SSI categories were defined by the criteria found in the Participant Use Data File of the ACS NSQIP. ${ }^{12}$ These definitions were also based on criteria set by the Centers for Disease Control (CDC). ${ }^{13}$ The primary outcome was the occurrence of 30-day superficial SSI (cellulitis) after hysterectomy. Cellulitis was defined as an infection that involved only skin or subcutaneous tissue of the surgical incision. Secondary outcomes were the occurrence of deep and organ-space SSI and urinary tract infection after hysterectomy. Deep and organspace SSI included infections involving deep soft tissues (fascia and muscle) at and around the surgical incision, as well as infections in any part of the body that was opened or manipulated during the operative procedure. This includes vaginal cuff cellulitis and vaginal cuff abscess, peritonitis and pelvic abscess. Deep and organ-space SSI were considered as one category, as these two categories were difficult to distinguish when considering hysterectomy as the primary procedure. Finally, we examined postoperative urinary tract infection (UTI). UTI was defined by CDC criteria for symptomatic urinary tract infection and asymptomatic bacteriuria which take into account the recent use of indwelling catheters and the age of the patient. ${ }^{13}$

Descriptive statistics, Student $t$ test, Pearson $\mathrm{x}^{2}$, and Fisher exact test (two-sided) were performed for bivariate analysis. Three logistic regression models were conducted to further explore the associations of risks factors for 1) cellulitis, 2) deep and organ-space SSI, and 3) 
postoperative UTI after hysterectomy. ${ }^{8,9}$ Variables associated with SSI were identified for potential inclusion in the final model based on bivariate analysis $(\mathrm{p}<.1)$. Variables were added to the model in a stepwise fashion utilizing forward selection ( $\mathrm{p} \leq 05)$. Adjusted Odds Ratios (AOR) and 95\% confidence intervals (CI) were calculated. Statistical analysis was performed using STATA 11.0 and SAS 9.2.

\section{Results}

A total of 23,569 participants were classified as undergoing a gynecologic procedure in the 2005-09 ACS NSQIP participant use dataset. The following women were excluded from the final analysis: 1) male gender ( $\mathrm{n}=51), 2)$ women with the diagnosis of current pregnancy $(\mathrm{n}=416), 3)$ surgical procedure within 30 days prior to hysterectomy ( $\mathrm{n}=185), 4)$ CPT-4 code inconsistent with hysterectomy $(\mathrm{n}=8,943), 5)$ CPT-4 code indicating pelvic exenteration procedure at the time of hysterectomy $(\mathrm{n}=10)$, and 6$)$ women with diagnosis of preoperative infection including sepsis, SIRS and septic shock immediately prior to hysterectomy $(n=142)$. A total of 13,822 women underwent hysterectomy and were included in our final analysis.

\section{Cellulitis}

The overall occurrence of cellulitis (superficial SSI) after hysterectomy was $1.6 \%$ (n/ $\mathrm{N}=221 / 13,822)$. Four $(0.03 \%)$ women were diagnosed with both postoperative cellulitis and deep or organ-space SSI. Twelve $(0.08 \%)$ women were diagnosed with both postoperative cellulitis and UTI. Variables associated with cellulitis on bivariate analysis included diabetes mellitus ( $p<.001)$, BMI category, $(\mathrm{p}<.001)$, preoperative ascites $(\mathrm{p}<.01)$, unintentional weight loss $(\mathrm{p}=.02)$, hysterectomy for cancer $(\mathrm{p}<.001)$, ASA class 3 or greater $(\mathrm{p}<.001)$, work relative value unit $(\mathrm{p}<.001)$, use of general anesthesia $(\mathrm{p}=.001)$ and an operative time > $75^{\text {th }}$ percentile $(\mathrm{p}<.001)($ Table 1$)$.

Variables associated with 30-day postoperative cellulitis on multivariate logistic regression were route of hysterectomy with an adjusted odds ratio (AOR) of 3.74 (95\% CI 2.26-6.22) for laparotomy incisions compared to vaginal approach, operative time $>75^{\text {th }}$ percentile $(\mathrm{AOR}=1.84,95 \%$ CI 1.40-2.44), ASA Class 3 or greater (AOR 1.79, 95\% CI 1.31-2.43), morbid obesity (BMI $\geq 40 \mathrm{~kg} / \mathrm{m}^{2}$ ) (AOR 2.65, 95\% CI 1.85-3.80), and diabetes mellitus (AOR 1.54, 95\% CI 1.06-2.24) (Table 2).

\section{Deep and organ-space SSI}

The occurrence of deep and organ-space SSI was $1.1 \%(\mathrm{n} / \mathrm{N}=154 / 13,822)$ after hysterectomy. No women were categorized as having both a deep space SSI and an organspace SSI. Twenty-one $(0.1 \%)$ women were diagnosed with both postoperative deep/organspace SSI and UTI. Variables associated with deep and organ-space SSI on bivariate analysis included race $(\mathrm{p}=.001)$, diabetes mellitus $(\mathrm{p}<.01)$, history of CVA with neurologic deficit $(\mathrm{p}<.01)$, current smoking $(\mathrm{p}=.001)$, obesity category $(\mathrm{p}=.11)$, preoperative ascites $(\mathrm{p}=$. $04)$, preoperative anemia $(\mathrm{p}<.01)$, ASA Class 3 or greater $(\mathrm{p}<.001)$, and an operative time $>$ $75^{\text {th }}$ percentile $(\mathrm{p}=.03)$. (Table 3$)$

Variables associated with deep and organ-space SSI on multivariate logistic regression included ASA $\geq$ Class 3 (AOR 1.81, 95\% CI 1.25-2.62), current smoking (AOR 1.99, 95\% CI 1.40-2.83), history of CVA with neurologic deficit (AOR 4.41, 95\% CI 1.54-12.65), preoperative anemia (AOR 1.72, 95\% CI 1.21-2.43), and morbid obesity (AOR 2.23, 95\% CI 1.43-3.49) (Table 4). When we examined hysterectomy route, both by abdominal incisions and by vaginal cuff incisions, with deep and organ-space SSI, we did not find any significant associations. 


\section{Urinary tract infection}

Postoperative UTI occurred in $2.7 \%$ ( $\mathrm{n} / \mathrm{N}=370 / 13,822)$ of women after hysterectomy. Variables associated with postoperative UTI on bivariate analysis included history of CVA with neurologic deficit $(\mathrm{p}=.01)$, ASA Class 3 or greater $(\mathrm{p}<.01)$, and an operative time $>75^{\text {th }}$ percentile $(\mathrm{p}<.001)$ (Table 5). Variables associated with postoperative UTI on multivariate logistic regression were a history of CVA with neurologic deficit (AOR 3.29, $95 \%$ CI 1.41-7.70), current corticosteroid use (AOR 2.37, 95\% CI 1.14-4.90), and operative time > $75^{\text {th }}$ percentile (AOR $1.86,95 \%$ CI 1.52-2.29) (Table 6).

\section{Occurrence of SSI by route of hysterectomy}

When we examined six different routes of hysterectomy (TAH, SCH, TLH, LASCH, LAVH, and TVH), we noticed similarities in the occurrence of SSI by abdominal incision type (Table 7). We examined routes of hysterectomy solely based on abdominal incisions (laparotomy, laparoscopic incisions, and no abdominal incisions) and noted that route of hysterectomy was associated with superficial SSI, but not deep/organ-space SSI or postoperative UTI. Finally, we examined the association of post-hysterectomy SSI by the presence or absence of vaginal cuff incisions (supracervical hysterectomy vs. vaginal colpotomy) and found no association with any postoperative SSI.

\section{Comment}

We found the overall occurrence of both 30-day cellulitis (superficial SSI) and deep and organ-space SSI after hysterectomy to be $2.7 \%$. The occurrence of UTI after hysterectomy was $3.0 \%$.

We identified the following risk factors were associated with the occurrence of postoperative cellulitis: hysterectomy route, operative time greater than the $75^{\text {th }}$ percentile (149 minutes), ASA class 3 or greater, diabetes mellitus, and obesity category (BMI $\geq 40 \mathrm{~kg}$ / $\mathrm{m}^{2}$ ). We did not find smoking status or hysterectomy for gynecologic cancer to be independent risk factors for postoperative cellulitis.

Our finding of the decreased occurrence of superficial SSI after vaginal approach for hysterectomy reaffirms the long appreciated role for vaginal hysterectomy as the route of choice for hysterectomy. ${ }^{14-16}$ Laparotomy independently increased the risk of superficial SSI after hysterectomy. A trend was seen for increased SSI with trocar incisions (minimallyinvasive hysterectomies), but this was not statistically significant.

Our findings add to prior work utilizing National Healthcare Safety Network (NHSN) data to examine SSI. ${ }^{2,17}$ The NHSN is an internet-based surveillance system, used by the CDC, to monitor hospital acquired infections including SSIs. ${ }^{18}$ Originally, the NHSN based riskadjustment for all SSI was based on Culver et al.'s predictive model incorporating wound classification, ASA classification, and operative time. ${ }^{11}$ Using these risk factors, Edwards et al. analyzed nearly 7,000 hysterectomies reported to the NHSN. The occurrence of all postoperative SSIs (superficial, deep and organ-space) after TVH was $0.9 \%$ and TAH was $1.7 \% .^{2}$ Unlike the reports by Culver and Edwards, our study seeks to identify risk factors for SSI that are more specific to hysterectomy. By examining various possible risk factors, our study suggests additional risk factors, such as route of hysterectomy, preoperative anemia, smoking status, and history of CVA that should be considered in future studies that examine SSI after hysterectomy.

Our findings are based on multi-institutional data collected in a standardized fashion. Olsen et al. performed a multi-center retrospective case-control study on approximately 800 patients after TAH and TVH. The cases and controls were collected using International 
Classification of Diseases, Ninth Revision, Clinical Modification [ICD-9-CM] procedure codes for hysterectomy from 4 participating CDC Prevention Epicenter Program hospitals from 2003 to 2005 . Both BMI $>35 \mathrm{~kg} / \mathrm{m}^{2}$ and intra-or postoperative blood transfusion were identified as independent risk factors for superficial SSI after hysterectomy via laparotomy. ${ }^{3}$ Similarly, a single institution chart review also found obesity $\left(\right.$ BMI $\geq 30 \mathrm{~kg} / \mathrm{m}^{2}$ ), and blood transfusion (pre-, intra-, and postoperative) to be associated with all SSI after abdominal hysterectomy. ${ }^{4}$ However, others have found obesity (BMI $\geq 30 \mathrm{~kg} / \mathrm{m}^{2}$ ) not to be a risk factor for postoperative complications after gynecologic surgery. ${ }^{19} \mathrm{We}$ found that by considering higher BMI than $30 \mathrm{~kg} / \mathrm{m}^{2}$, BMI was identified as a risk-factor for superficial SSI (cellulitis). In our larger multi-center analysis, we did not find an association between preoperative transfusion and SSI. Although intraoperative transfusion was identified in our bivariate analysis to be associated with cellulitis and deep/organ-space SSI, we did not find a statistically significant association between intraoperative transfusion and SSI after adjusting for other variables. The differences in our findings and previous reports regarding transfusion (both pre- and intraoperative) as a risk factor for SSI after hysterectomy are likely related to the robust sample size of our study.

We identified risk-factors associated with deep and organ-space SSI after hysterectomy that included preoperative anemia and history of CVA, which may be reflective of chronic preoperative systemic disease. These risk-factors are in addition to risk-factors of ASA class 3 or greater, current smoking status, and morbid obesity (BMI $\geq 40 \mathrm{~kg} / \mathrm{m}^{2}$ ). We did not find a statistically significant difference in deep and organ-space SSI between different hysterectomy routes. We hypothesize that our findings of increased association of both preoperative anemia and history of CVA with deep and organ-space SSI may reflect a decrease of the body's ability to respond to stressors of surgery and combat postoperative infection. We found an association between preoperative CVA with residual neurologic symptoms and the risk of deep and organ-space SSI. CVA has been noted to be significantly associated with any adverse postoperative event. ${ }^{20} \mathrm{We}$ believe we may have observed this relationship as CVA with residual neurologic symptoms is a risk factor for functional dependence. ${ }^{21}$ Chen et al found functional dependence to be an independent risk factor for postoperative SSI, specifically Methicillin-resistant Staphylococcus aureus SSI, in older adults. ${ }^{22}$

We did not find differences in risk factors for deep and organ-space SSI when we examined these infections separately. We ultimately chose to combine these two categories together when examining SSI after hysterectomy. We believe that deep and organ-space SSI, though defined distinctly by the ACS NSQIP and CDC criteria, are functionally the same event following hysterectomy due to the incision at the vaginal cuff. Following a hysterectomy, an example of a deep SSI would be considered a vaginal cuff abscess. We believe that a pelvic abscess that drains through the vaginal cuff, which would be considered as a deep space SSI draining through the surgical incision, is essentially similar to a pelvic abscess that requires drainage through interventional radiology which would alternatively be categorized as an organ-space SSI. Due to the overlap between these terms, we elected to combine deep and organ-space SSI.

The risk factors associated with postoperative UTI after hysterectomy were history of CVA with neurologic deficit, chronic steroid use, and operative time greater than the $75^{\text {th }}$ percentile. We found the occurrence of 30-day postoperative UTI was $3.0 \%(n=402)$ after hysterectomy. Unfortunately, we did not have information on catheter-use or duration due to limits of the dataset.

One hundred forty-two women were identified as having preoperative systemic infection including sepsis, septic shock, and systemic inflammatory response syndrome and were 
excluded due to the inherent difference in these cases from women undergoing scheduled elective surgery. Though these conditions may be associated with a greater risk of postoperative SSI, the small numbers and the various different causes of systemic infection made it difficult to draw conclusions in the current study.

Our study has many limitations. The first is that our analysis was limited to the variables that existed in the database. For example, we were limited by the ACS NSQIP definition of deep and organ-space SSI and therefore we were also unable to distinguish between pelvic abscesses, vaginal cuff cellulitis, or fasciitis.

Secondly, specific variables were not collected in the general ACS-NSQIP dataset that would have enhanced our study findings. For example, the type and timing of preoperative prophylactic antibiotic administration, a factor well-linked to postoperative infection, ${ }^{23,24}$ were not available in the database. Another limitation of this dataset was the lack of information about the indication for hysterectomy. Surgical procedures were categorized by CPT codes alone. The occurrence of postoperative urinary tract infection after prolapse or anti-incontinence surgery has been reported to be higher than that found in our study. ${ }^{25}$ As women were selected for inclusion in this study based on hysterectomy and not prolapse or incontinence procedures, we were not able to determine the occurrence of urinary tract infection after prolapse or incontinence procedures in our current analysis.

We did not find an association with hysterectomies performed for gynecologic cancer and SSI, based on CPT-4 codes. This finding may also be due to the lack of specific information in the dataset regarding cancer stage, grade and pathology in the ACS NSQIP dataset. We were limited to identification of procedures for gynecologic cancer based on CPT-4 codes indicating radical dissection and lymphadenectomies. Additionally, some hysterectomies for cancer requiring bowel resection may have been coded primarily as colon surgery, and therefore not included in our analysis. We did examine all cancer variables available in the ACS NSQIP dataset (including known disseminated tumor, chemotherapy or radiation therapy within 30 days prior to procedure, and known CNS tumor) both individually and as a composite group and did not find a statistically significant association with SSI. This, again, likely reflects the limitation of the dataset because it does not include cancer stage, grade and pathology.

Lastly, hospital participation in the ACS NSQIP is voluntary and confidential which may introduce selection bias; however, as of 2009, over 320 hospitals were participating in the ACS NSQIP program including a wide-range of community-hospitals and tertiary care centers. The ACS NSQIP participant use data files do not allow for identification of participating hospital within the dataset and therefore we were not able to account for the effect of clustering of observations within centers. However, previous investigators have demonstrated that the clustering effect from the ASC NSQIP for other end points is minimal and did not change the overall adjusted outcomes. ${ }^{5,26}$

Our study suggests that numerous factors, including hysterectomy route, operative time, diabetes mellitus, ASA Class 23 , BMI, smoking status, preoperative anemia, CVA with neurologic deficit, and corticosteroid use are associated with SSI after hysterectomy. Development of a predictive model for SSI after all types of hysterectomy is needed. Unfortunately, we cannot develop a predictive model with this current work due to lack of a validation cohort.

Decreasing preventable hospital acquired infections is important for the sake of quality patient care. In light of the recent national CMS mandate, requiring all Medicare-certified hospitals to publicly report data and outcome measures, prevention of SSI will soon become important for a hospital's financial stability as well. ${ }^{1}$ The ACS NSQIP program to improve 
quality and patient safety has succeeded by providing timely, consistent, confidential, riskadjusted feedback to participating institutions on the institutional occurrence of a wide-range of postoperative complications. ${ }^{5}$ Institutions can then immediately identify systems and strategies to improve patient outcomes in areas they identify their institution to be outlying. ${ }^{5}$ This confidential risk-adjusted program has begun to improve surgical outcomes. Knowledge of the baseline occurrence of postoperative SSI after different routes of hysterectomy and associated risk factors is important to improve patient safety after hysterectomy by helping to identify modifiable factors to prevent SSIs. As CMS enforces mandatory public reporting of postoperative SSI after hysterectomy without risk-adjustment specific to hysterectomy, careful monitoring must be employed to identify unintended consequences.

\section{Acknowledgments}

The American College of Surgeons National Surgical Quality Improvement Program and the hospitals participating in the ACS NSQIP are the source of the data used herein; they have not verified and are not responsible for the statistical validity of the data analysis or the conclusions derived by the authors.

Financial Support: This work was supported in part by a grant from the Claude D. Pepper Older Americans Independence Center at Yale University School of Medicine (P30AG021342 NIH/NIA) and an award from the National Institutes on Aging (R03AG042363-01).

\section{References}

1. Centers for Medicare and Medicaid Services (CMS). HHS. [Accessed 12/19, 2012] Final rule CMS-1498-F. federal register volume 75, number 157 (monday, august 16, 2010)] [rules and regulations] [pages 50041-50677]from the federal register online via the government printing office. [www.gpo.gov][FR doc no: 2010-19092. http://www.gpo.gov/fdsys/pkg/FR-2011-08-18/html/ 2011-19719.htm:

2. Edwards JR, Peterson KD, Andrus ML, et al. National healthcare safety network (NHSN) report, data summary for 2006 through 2007, issued november 2008. Am J Infect Control. 2008; 36(9): 609-626. [PubMed: 18992647]

3. Olsen MA, Higham-Kessler J, Yokoe DS, et al. Developing a risk stratification model for surgical site infection after abdominal hysterectomy. Infect Control Hosp Epidemiol. 2009; 30(11):10771083. [PubMed: 19803722]

4. Young H, Bliss R, Carey JC, Price CS. Beyond core measures: Identifying modifiable risk factors for prevention of surgical site infection after elective total abdominal hysterectomy. Surg Infect (Larchmt). 2011; 12(6):491-496. [PubMed: 22142313]

5. Henderson WG, Daley J. Design and statistical methodology of the national surgical quality improvement program: Why is it what it is? Am J Surg. 2009; 198(5 Suppl):S19-27. [PubMed: 19874930]

6. Erekson EA, Yip SO, Ciarleglio MM, Fried TR. Postoperative complications after gynecologic surgery. Obstet Gynecol. 2011; 118(4):785-793. [PubMed: 21934441]

7. national institutes of health. Clinical guidelines on the identification, evaluation, and treatment of overweight and obesity in adults--the evidence report. Obes Res. 1998; 6(Suppl 2):51S-209S. [PubMed: 9813653]

8. Wu WC, Schifftner TL, Henderson WG, et al. Preoperative hematocrit levels and postoperative outcomes in older patients undergoing noncardiac surgery. JAMA. 2007; 297(22):2481-2488. [PubMed: 17565082]

9. Heisler CA, Aletti GD, Weaver AL, Melton LJ 3rd, Cliby WA, Gebhart JB. Improving quality of care: Development of a risk-adjusted perioperative morbidity model for vaginal hysterectomy. Am J Obstet Gynecol. 2010; 202(2):137.e1-137.e5. [PubMed: 19691949]

10. Dowdy SC, Borah BJ, Bakkum-Gamez JN, et al. Factors predictive of postoperative morbidity and cost in patients with endometrial cancer. Obstet Gynecol. 2012; 120(6):1419-1427. [PubMed: 23168769] 
11. Culver DH, Horan TC, Gaynes RP, et al. Surgical wound infection rates by wound class, operative procedure, and patient risk index. national nosocomial infections surveillance system. Am J Med. 1991; 91(3B):152S-157S. [PubMed: 1656747]

12. American college of surgeons national surgical quality improvement program. [Accessed 8/15/2012] participant use data file. http://site.acsnsqip.org/participant-use-data-file/

13. Horan TC, Andrus M, Dudeck MA. CDC/NHSN surveillance definition of health care-associated infection and criteria for specific types of infections in the acute care setting. Am J Infect Control. 2008; 36(5):309-332. [PubMed: 18538699]

14. Kovac SR. Guidelines to determine the route of hysterectomy. Obstet Gynecol. 1995; 85(1):18-23. [PubMed: 7800317]

15. Falcone T, Walters MD. Hysterectomy for benign disease. Obstet Gynecol. 2008; 111(3):753-767. [PubMed: 18310381]

16. American College of Obstetrics \& Gynecology. ACOG committee opinion no. 444: Choosing the route of hysterectomy for benign disease. 2009.

17. Mu Y, Edwards JR, Horan TC, Berrios-Torres SI, Fridkin SK. Improving risk-adjusted measures of surgical site infection for the national healthcare safety network. Infect Control Hosp Epidemiol. 2011; 32(10):970-986. [PubMed: 21931247]

18. Centers for disease control and prevention. national healthcare safety network (NHSN). [Accessed 8/15/2012] http://www.cdc.gov/nhsn/

19. Chen CC, Collins SA, Rodgers AK, Paraiso MF, Walters MD, Barber MD. Perioperative complications in obese women vs normal-weight women who undergo vaginal surgery. Am.J.Obstet.Gynecol. 2007; 197(1):98.e1-98.e8. [PubMed: 17618776]

20. Liu LL, Leung JM. Predicting adverse postoperative outcomes in patients aged 80 years or older. J Am Geriatr Soc. 2000; 48(4):405-412. [PubMed: 10798467]

21. Fernandes TG, Goulart AC, Santos-Junior WR, Alencar AP, Bensenor IM, Lotufo PA. Educational levels and the functional dependence of ischemic stroke survivors. Cad Saude Publica. 2012; 28(8):1581-1590. [PubMed: 22892977]

22. Chen TY, Anderson DJ, Chopra T, Choi Y, Schmader KE, Kaye KS. Poor functional status is an independent predictor of surgical site infections due to methicillin-resistant staphylococcus aureus in older adults. J Am Geriatr Soc. 2010; 58(3):527-532. [PubMed: 20158557]

23. Rosenberger LH, Politano AD, Sawyer RG. The surgical care improvement project and prevention of post-operative infection, including surgical site infection. Surg Infect (Larchmt). 2011; 12(3): 163-168. [PubMed: 21767148]

24. American College of Obstetrics \& Gynecology. ACOG practice bulletin no. 104: Antibiotic prophylaxis for gynecologic procedures. 2009. Reaffirmed 2011

25. Sutkin G, Alperin M, Meyn L, Wiesenfeld HC, Ellison R, Zyczynski HM. Symptomatic urinary tract infections after surgery for prolapse and/or incontinence. Int.Urogynecol.J. 2010; 21(8):955961. [PubMed: 20354678]

26. Cohen ME, Dimick JB, Bilimoria KY, Ko CY, Richards K, Hall BL. Risk adjustment in the American College of Surgeons National Surgical Quality Improvement Program: a comparison of logistic versus hierarchical modeling. J.Am.Coll.Surg. 2009; 209(6):687-693. [PubMed: 19959035] 
Table 1

Demographic and clinical characteristics of 30-day postoperative superficial SSI after hysterectomy (N $=13,822$ )

\begin{tabular}{|c|c|c|c|}
\hline Variable & $\begin{array}{l}\text { Cellulitis } \\
(n=221)\end{array}$ & $\begin{array}{l}\text { No Cellulitis } \\
(n=13,601)\end{array}$ & $P$ \\
\hline Age category & & & 1.0 \\
\hline$<80$ years old & $218(98.6)$ & $13,378(98.4)$ & \\
\hline 280 years old & $3(1.4)$ & $223(1.6)$ & \\
\hline Race & & & .49 \\
\hline White & $129(58.4)$ & $8,265(60.8)$ & \\
\hline Ethnicity & & & .14 \\
\hline Hispanic & $27(12.2)$ & $2,180(16.0)$ & \\
\hline Diabetes mellitus & $41(18.6)$ & $982(7.2)$ & $<.001$ \\
\hline History of CVA with neurologic deficit & $1(0.5)$ & $65(0.5)$ & 1.0 \\
\hline Current smoker & $51(23.1)$ & 2,671 (19.6) & .20 \\
\hline BMI category & & & $<.001$ \\
\hline$<30 \mathrm{~kg} / \mathrm{m}^{2}$ & $78(35.3)$ & $7,598(55.9)$ & \\
\hline$\geq 30$ and $<40 \mathrm{~kg} / \mathrm{m}^{2}$ & $74(33.5)$ & $4,564(33.6)$ & \\
\hline$\geq 40 \mathrm{~kg} / \mathrm{m}^{2}$ & $69(31.2)$ & $1,439(10.6)$ & \\
\hline Ascites & $6(2.7)$ & $104(0.8)$ & $<.01$ \\
\hline Unintentional weight $\operatorname{loss}^{a}$ & $4(1.8)$ & $62(0.5)$ & .02 \\
\hline Functional status (dependent for ADLs) & $2(0.9)$ & $97(0.7)$ & .67 \\
\hline Hysterectomy for gynecologic cancer & $32(14.5)$ & $871(6.4)$ & $<.001$ \\
\hline Preoperative anemia (Hct < $36 \%)$ & $48(22.3)$ & $2,976(22.8)$ & .94 \\
\hline Preoperative Creatinine $>1.5 \mathrm{mg} / \mathrm{dL}$ & $3(1.8)$ & $75(0.9)$ & .18 \\
\hline ASA Class 3 or higher & $93(42.1)$ & $2,521(18.5)$ & $<.001$ \\
\hline Intraoperative blood transfusion & $15(6.8)$ & $329(2.4)$ & $<.001$ \\
\hline Work Relative Value Unit (mean, \pm SD) & $18.7( \pm 5.1)$ & $17.3( \pm 3.8)$ & $<.001$ \\
\hline $\begin{array}{l}\text { Operative time } \\
>75^{\text {th }} \text { percentile duration }\end{array}$ & $93(42.1)$ & $3,378(24.8)$ & $<.001$ \\
\hline Type of anesthesia (general) & $221(100.0)$ & $13,111(96.4)$ & .001 \\
\hline Wound class & & & .06 \\
\hline 1-Clean & 0 & $33(0.2)$ & \\
\hline 2-Clean/contaminated & $215(97.3)$ & $13,443(98.8)$ & \\
\hline 3-contaiminated & $5(2.3)$ & $92(0.7)$ & \\
\hline 4-dirty & $1(0.5)$ & $33(0.2)$ & \\
\hline
\end{tabular}

All values listed as $\mathrm{n}(\%)$ unless otherwise specified

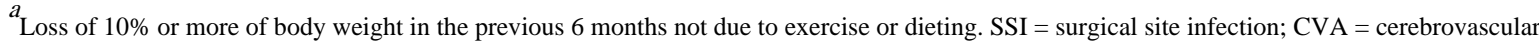
accident; $\mathrm{BMI}=$ body mass index; $\mathrm{SD}=$ standard deviation; $\mathrm{ADL}=$ activities of daily living; Hct= hematocrit; ASA = American Society of Anesthesiologists 
Table 2

Losistic Resression Model for Association of Cellulitis after Hysterectomy

\begin{tabular}{lrrr}
\hline Variable & $\begin{array}{c}\text { Adjusted } \\
\text { OR }\end{array}$ & 95\% CI & \multicolumn{1}{c}{$\boldsymbol{P}$} \\
\hline Route of hysterectomy & 1 & -- & -- \\
$\quad$ TVH (referent) & 3.74 & $(2.26,6.22)$ & $<.001$ \\
$\quad$ Laparotomy & 1.45 & $(0.83,2.56)$ & .20 \\
$\quad$ Laparoscopic & 1.84 & $(1.40,2.44)$ & $<.001$ \\
Operative time $>75^{\text {th }}$ percentile duration & 1.79 & $(1.31,2.43)$ & $<.001$ \\
ASA Class 3 or higher & & & \\
BMI category & 1 & & -- \\
$\quad$ BMI $<30 \mathrm{~kg} / \mathrm{m}^{2}($ referent $)$ & 1.31 & $(0.94,1.81)$ & .11 \\
$\quad$ BMI $\geq 30 \mathrm{and}<40 \mathrm{~kg} / \mathrm{m}^{2}$ & 2.65 & $(1.85,3.80)$ & $<.001$ \\
$\quad$ BMI $\geq 40 \mathrm{~kg} / \mathrm{m}^{2}$ & 1.54 & $(1.06,2.24)$ & .02 \\
\hline Diabetes mellitus & & & \\
\hline
\end{tabular}

Laparotomy included total abdominal hysterectomy and supracervical hysterectomy Laparoscopic included laparoscopic-assisted vaginal hysterectomy, total laparoscopic hysterectomy, and laparoscopic supracervical hysterectomy.

$\mathrm{OR}=$ Odds Ratio $\mathbf{C I}=$ Confidence Interval TVH = total vaginal hysterectomy; ASA= American Society of Anesthesiologists; BMI= body mass index 
Table 3

Demographic and clinical characteristics of 30-day postoperative deep or organ-space SSI after hysterectomy $(\mathrm{N}=13,822)$

\begin{tabular}{|c|c|c|c|}
\hline Variable & $\begin{array}{l}\text { Deep/organ-space } \\
\text { SSI } \\
(n=154)\end{array}$ & $\begin{array}{l}\text { No deep/organ- } \\
\text { space SSI } \\
(n=13,668)\end{array}$ & $P$ \\
\hline Age category & & & 1.0 \\
\hline$<80$ years old & $152(98.7)$ & $13,444(98.4)$ & \\
\hline$\geq 80$ years old & $2(1.3)$ & $224(1.6)$ & \\
\hline Race & & & .001 \\
\hline White & $73(47.4)$ & $8,321(60.9)$ & \\
\hline Ethnicity & & & .12 \\
\hline Hispanic & $32(20.8)$ & $2,175(15.9)$ & \\
\hline Diabetes mellitus & $23(14.9)$ & $1,000(7.3)$ & $<.01$ \\
\hline History of CVA with neurologic deficit & $4(2.6)$ & $62(0.5)$ & $<.01$ \\
\hline Current smoker & $47(30.5)$ & $2,675(19.6)$ & .001 \\
\hline BMI category & & & $<.001$ \\
\hline$<30 \mathrm{~kg} / \mathrm{m}^{2}$ & $68(44.2)$ & $7,608(55.7)$ & \\
\hline$\geq 30$ and $<40 \mathrm{~kg} / \mathrm{m}^{2}$ & $50(32.5)$ & $4,588(33.6)$ & \\
\hline$\geq 40 \mathrm{~kg} / \mathrm{m}^{2}$ & $36(23.4)$ & $1,472(10.8)$ & \\
\hline Ascites & $4(2.6)$ & $106(0.8)$ & .04 \\
\hline Unintentional weight $\operatorname{loss}^{a}$ & $2(1.3)$ & $64(0.5)$ & .17 \\
\hline Functional status (dependent for ADLs) & $2(1.3)$ & $97(0.7)$ & .30 \\
\hline Hysterectomy for gynecologic cancer & $13(8.4)$ & $890(6.5)$ & .32 \\
\hline Preoperative anemia $(\mathrm{Hct}<36 \%)$ & $50(33.8)$ & $2,974(22.7)$ & $<.01$ \\
\hline Preoperative Creatinine $>1.5 \mathrm{mg} / \mathrm{dL}$ & $3(2.8)$ & $75(0.9)$ & .08 \\
\hline ASA Class 3 or higher & $54(35.1)$ & $2,560(18.7)$ & $<.001$ \\
\hline Intraoperative blood transfusion & $8(5.2)$ & $336(2.5)$ & .06 \\
\hline Work Relative Value Unit (Mean, \pm SD) & $17.8( \pm 4.6)$ & $17.3( \pm 3.8)$ & .13 \\
\hline $\begin{array}{l}\text { Operative time } \\
>75^{\text {th }} \text { percentile duration }\end{array}$ & $51(33.1)$ & $3,420(25.0)$ & .03 \\
\hline Type of anesthesia (general) & $148(96.1)$ & $13,184(96.5)$ & .82 \\
\hline Wound class & & & .16 \\
\hline 1-Clean & 0 & $33(0.2)$ & \\
\hline 2-Clean/contaminated & $150(97.4)$ & $13,508(98.8)$ & \\
\hline 3-contaiminated & $3(2.0)$ & $94(0.7)$ & \\
\hline 4-dirty & $1(0.7)$ & $33(0.2)$ & \\
\hline
\end{tabular}

All values listed as n (\%) unless otherwise specified

${ }^{a}$ Loss of $10 \%$ or more of body weight in the previous 6 months not due to exercise or dieting. SSI = surgical site infection; CVA = cerebrovascular accident; $\mathrm{BMI}=$ body mass index $\mathrm{SD}=$ standard deviation; $\mathrm{ADL}=$ activities of daily living; Hct= hematocrit; $\mathrm{ASA}=\mathrm{American}$ Society of Anesthesiologists 
Table 4

Logistic Regression Model for Association of Deep or Organ Space SSI after Hysterectomy

\begin{tabular}{lrrr}
\hline Variable & $\begin{array}{c}\text { Adjusted } \\
\text { OR }\end{array}$ & $\mathbf{9 5 \%}$ CI & \multicolumn{1}{c}{$\boldsymbol{P}$} \\
\hline ASA Class 3 or higher & 1.81 & $(1.25,2.62)$ & $<.01$ \\
Current smoker & 1.99 & $(1.40,2.83)$ & $<.001$ \\
History of CVA with neurologic deficit & 4.41 & $(1.54,12.65)$ & $<.01$ \\
Preoperative anemia $($ Hct $<36 \%)$ & 1.72 & $(1.21,2.43)$ & $<.01$ \\
BMI category & & & - \\
$\quad$ BMI $<30 \mathrm{~kg} / \mathrm{m}^{2}($ referent $)$ & 1 & & -- \\
BMI $\geq 30 \mathrm{and}<40 \mathrm{~kg} / \mathrm{m}^{2}$ & 1.19 & $(0.82,1.74)$ & .36 \\
BMI $\geq 40 \mathrm{~kg} / \mathrm{m}^{2}$ & 2.23 & $(1.43,3.49)$ & $<.001$ \\
\hline
\end{tabular}

$\mathrm{SSI}=$ surgical site infection $; \mathrm{OR}=$ Odds Ratio $; \mathrm{CI}=$ Confidence Interval; ASA= American Society of Anesthesiologists; $\mathrm{CVA}=$ cerebrovascular accident; Hct= hematocrit; $\mathrm{BMI}=$ body mass index 
Table 5

Demographic and clinical characteristics of 30-day postoperative UTI after hysterectomy $(\mathrm{N}=13,822)$

\begin{tabular}{|c|c|c|c|}
\hline Variable & $\begin{array}{l}\text { UTI } \\
(n=402)\end{array}$ & $\begin{array}{l}\text { No UTI } \\
(n=13,420)\end{array}$ & $P$ \\
\hline \multicolumn{4}{|l|}{ Age category } \\
\hline$<80$ years old & $392(97.5)$ & $13,204(98.4)$ & .16 \\
\hline$\geq 80$ years old & $10(2.5)$ & $216(1.6)$ & \\
\hline \multicolumn{4}{|l|}{ Race } \\
\hline White & $259(64.4)$ & $8,135(60.6)$ & .13 \\
\hline \multicolumn{4}{|l|}{ Ethnicity } \\
\hline Hispanic & $57(14.2)$ & $2,150(16.0)$ & .37 \\
\hline Diabetes mellitus & $23(5.7)$ & $1,000(7.5)$ & .21 \\
\hline History of CVA with neurologic deficit & $6(1.5)$ & $60(0.5)$ & .01 \\
\hline Current smoker & $90(22.4)$ & $2,632(19.6)$ & .18 \\
\hline BMI category & & & .42 \\
\hline$<30 \mathrm{~kg} / \mathrm{m}^{2}$ & $215(53.5)$ & $7,461(55.6)$ & \\
\hline$\geq 30$ and $<\mathrm{kg} / \mathrm{m}^{2}$ & $147(36.6)$ & $4,491(33.5)$ & \\
\hline$\geq 40 \mathrm{~kg} / \mathrm{m}^{2}$ & $40(10.0)$ & $1,468(10.9)$ & \\
\hline Ascites & $2(0.5)$ & $108(0.8)$ & .77 \\
\hline Unintentional weight $\operatorname{loss}^{a}$ & $4(1.0)$ & $62(0.5)$ & .13 \\
\hline Functional status (dependent for ADL) & $6(1.5)$ & $93(0.7)$ & .07 \\
\hline Hysterectomy for gynecologic cancer & $26(6.5)$ & $877(6.5)$ & 1.00 \\
\hline Preoperative anemia $(\mathrm{Hct}<36 \%)$ & $79(20.6)$ & $2,945(22.9)$ & .32 \\
\hline Preoperative Creatinine $>1.5 \mathrm{mg} / \mathrm{dL}$ & $3(1.2)$ & $75(0.9)$ & .51 \\
\hline ASA Class 3 or higher & $99(24.6)$ & $2,515(18.7)$ & $<.01$ \\
\hline Intraoperative blood transfusion & $9(2.2)$ & $335(2.5)$ & .87 \\
\hline Work relative value unit Mean, $\pm \mathrm{SD}$ & $17.1( \pm 3.8)$ & $17.3( \pm 3.8)$ & .33 \\
\hline $\begin{array}{l}\text { Operative time } \\
>75^{\text {th }} \text { percentile duration }\end{array}$ & $153(38.1)$ & $3,318(24.7)$ & $<.001$ \\
\hline Type of anesthesia (general) & $393(97.8)$ & $12,939(96.4)$ & .17 \\
\hline Wound class & & & .87 \\
\hline 1-Clean & 0 & $33(0.3)$ & \\
\hline 2-Clean/contaminated & $398(99.0)$ & $13,260(98.8)$ & \\
\hline 3-Contaiminated & $3(0.8)$ & $94(0.7)$ & \\
\hline 4-Dirty & $1(0.3)$ & $33(0.3)$ & \\
\hline
\end{tabular}

All values listed as n (\%) unless otherwise specified

a

Loss of $10 \%$ or more of body weight in the previous 6 months not due to exercise or dieting. UTI $=$ urinary tract infection; CVA $=$ cerebrovascular accident; $\mathrm{BMI}=$ body mass index; $\mathrm{SD}=$ standard deviation; $\mathrm{ADL}=$ activities of daily living; Hct= hematocrit; $\mathrm{ASA}=\mathrm{American}$ Society of Anesthesiologists 
Table 6

Logistic Regression Model for Association of UTI after Hysterectomy

\begin{tabular}{lrrr}
\hline Variable & $\begin{array}{c}\text { Adjusted } \\
\text { OR }\end{array}$ & 95\% CI & \multicolumn{1}{c}{$\boldsymbol{P}$} \\
\hline History of CVA with neurologic deficit & 3.29 & $(1.41,7.70)$ & $<.01$ \\
Current corticosteroid use & 2.37 & $(1.14,4.90)$ & .02 \\
Operative time $>75^{\text {th }}$ percentile duration & 1.86 & $(1.52,2.29)$ & $<.001$ \\
\hline
\end{tabular}

$\mathrm{UTI}=$ urinary tract infection; $\mathrm{OR}=$ Odds Ratio; $\mathrm{CI}=$ Confidence Interval; ASA= American Society of Anesthesiologists; $\mathrm{CVA}=$ cerebrovascular accident; Hct= hematocrit; $\mathrm{BMI}=$ body mass index 
Table 7

All 30-dav postoperative SSI and UTI by Hysterectomy Route $(\mathrm{N}=13,822)$

\begin{tabular}{lllllll}
\hline Type of SSI & N & TAH & SCH & TVH & LAVH & TLH \\
\hline No SSI & $13,081(94.6)$ & $5,069(93.8)$ & $688(94.0)$ & $2,921(95.3)$ & $2,094(94.3)$ & $837(95.2)$ \\
Cellulitis & $217(1.6)$ & $141(2.6)$ & $17(2.3)$ & $17(0.6)$ & $17(0.8)$ & $5(0.6)$ \\
Deep/Organ-Space & $154(1.1)$ & $67(1.2)$ & $8(1.1)$ & $32(1.0)$ & $33(1.5)$ & $4(0.5)$ \\
UTI & $370(2.7)$ & $128(2.4)$ & $19(2.6)$ & $94(3.1)$ & $76(3.4)$ & $33(3.8)$ \\
\hline
\end{tabular}

All values listed as $\mathrm{n}(\%)$ unless otherwise specified

$\mathrm{SSI}=$ surgical site infection; $\mathrm{UTI}=$ urinary tract infection; $\mathrm{TAH}=$ total abdominal hysterectomy $; \mathrm{SCH}=$ supracervical hysterectomy; $\mathrm{TVH}=$ total vaginal hysterectomy; $\mathrm{LAVH}=$ laparoscopic assisted vaginal hysterectomy; TLH = total laparoscopic hysterectomy; $\mathrm{LASCH}=$ laparoscopic supracervical hysterectomy 